\title{
Recent Advances in Reproductive Biotechnologies in Sheep and Goat
}

\author{
Basil Alexander ${ }^{1,2 *}$, Gabriela Mastromonaco ${ }^{1,3}$ and W. Allan King ${ }^{1}$ \\ ${ }^{1}$ Department of Biomedical Sciences, Ontario Veterinary College (OVC), University of Guelph, Ontario, Canada \\ ${ }^{2}$ Department of Farm Animal Production and Health, Faculty of Veterinary Medicine and Animal Science, University of Peradeniya, Sri Lanka \\ ${ }^{3}$ Reproductive Physiology, Toronto Zoo, 361A Old Finch Avenue, Scarborough, ON, M1B 5K7
}

Keywords: Reproductive biotechnologies; In vitro/in vivo fertilization; Artificial insemination; Somatic cell nuclear transfer; Transgenesis

\section{Contents}

This review focuses on the platform of recent advances in reproductive biotechnologies in sheep and goat. Here, we discuss some aspects of veterinary and biomedical importance in artificial insemination using sexed semen, in vitro/in vivo fertilization, interspecies in vitro fertilization, multiple ovulation and embryo transfer (MOET), somatic cell nuclear transfer and transgenic animal production in sheep and goat. Some of these technologies are already widely used in the cattle industry, and some are new to the goat and sheep industry.

\section{Introduction}

The world sheep and goat populations in 2006 were recorded as 416 and 489 million, respectively [1]. Reproductive biotechnologies are playing an increasingly important role in the production and management of these species. Animal biotechnology encompasses the application of science and engineering principles to the processing or production of materials to provide services or goods for human use [2]. Examples of current animal biotechnologies include artificial insemination using fresh, frozen or sexed semen, embryo transfer using fresh or frozen in vivo or in vitro produced embryos, cloning using somatic cell nuclear transfer procedures and production of transgenic animals. Recent advances in reproductive biotechnologies have shown important developments in the technologies and their delivery that promise to yield significant benefits for their application within the livestock industry as well as in biomedical sciences. This review focuses on the recent advances of biotechnologies in sheep and goats.

\section{Artificial Insemination (AI)}

Artificial insemination is the procedure involving the mechanical deposition of pre-collected semen into the uterus of an estrous female by a technician. The widespread commercial application of $\mathrm{AI}$, a robust tool in livestock breeding, began in earnest in the 1950's after researchers developed methods to successfully freeze cattle semen [3]. This technology, which is the most extensively applied reproductive biotechnology in the world, has many valuable advantages such as reducing venereal diseases, rapidly increasing genetic merits of the production animals through selective breeding and eliminating lethal alleles. The potential to pass high genetic merits of a selected male to thousands of females, makes this a far more efficient technology for producing large numbers $\left(1.5 \times 10^{8}\right)$ of offspring per year compared to female based technologies, such as embryo transfer (ET), which can only produce a few progeny from a selected female. More recently, the advent of separation of sperm into $\mathrm{X}$ - and Y-chromosome fractions using flow cytometry has added a new dimension to livestock production [4].
Since the first report of live rabbit pups of predetermined sex using $X$ and $Y$-enriched sorted semen over 20 years ago [5], there have been more than 40,000 births of live animals resulting from the so- called Beltsville sperm sexing technology [4]. This sperm sexing technology has proven to be a reliable and more efficient method of obtaining predetermined sex in animals compared to other relatively wasteful methods of embryo sexing and pre-implantation genetic diagnosis [6 - 8]. Live offspring born from fresh sex- sorted semen have been reported in many species including cattle [9], pigs [10,11], horses [12,13] and sheep [14,15]. As the sorting procedure can separate sperm only at a speed of approximately 10 million per hour, inseminations have to be carried out using limited numbers of sperm in each insemination dose compared to the conventional standards for AI. To obtain high success rates with sorted semen AI, most trials have been carried out using fresh sorted semen, nevertheless, use of frozen sorted semen is ultimately more beneficial to the livestock industry as it can be stored for long duration and easy to transport anywhere in the world.

\section{Semen sexing technology}

Semen sexing is the process of separating spermatozoa into two subpopulations containing X-chromosome and Y-chromosome bearing spermatozoa. In theory, use of the X-bearing spermatozoa fraction for insemination will result in female progeny, while the Y-bearing spermatozoa fraction will give male progeny. Considerable efforts have been made in this area over the past 30-40 years, but only recently has there been considerable progress, particularly in cattle [16]. The most commonly applied technique for the separation of a fresh semen sample into $\mathrm{X}$ and $\mathrm{Y}$-chromosome bearing fractions is fluorescence activated cell sorting (FACS). The concept behind this technique is described below:

\section{Fluorescence activated cell sorting (FACS)}

This technique involves the separation of $\mathrm{X}$ - and $\mathrm{Y}$ - bearing spermatozoa in small quantities based on the DNA content of the spermatozoa so that they can then be used in in vitro fertilization and $\mathrm{AI}$ programs [17]. The procedure is relatively slow and requires expensive infrastructure at least for mass scale commercial application. The technique is based on the biological principle that the

*Corresponding author: Dr. Basil Alexander, Department of Farm Animal Production and Health, Faculty of Veterinary Medicine and Animal Science, University of Peradeniya, Peradeniya, Sri Lanka Fax: 009481238 9136; Email: baalexan@uoguelph.ca or pabda@pdn.ac.lk

Accepted September 23, 2010; Published September 29, 2010

Citation: Alexander B, Mastromonaco G, King WA (2010) Recent Advances in Reproductive Biotechnologies in Sheep and Goat. J Veterinar Sci Technol 1:101. doi:10.4172/2157-7579.1000101

Copyright: (c) 2010 Alexander B, et al. This is an open-access article distributed under the terms of the Creative Commons Attribution License, which permits unrestricted use, distribution, and reproduction in any medium, provided the original author and source are credited. 


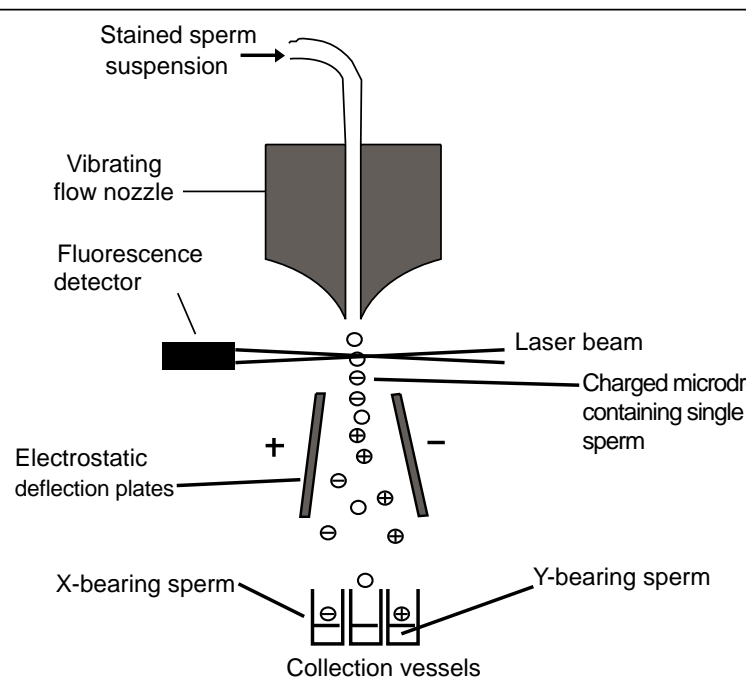

Figure 1: Schematic representation of the concept behind the Florescent Activated Cell Sorting technique used in separation of $X$ - and Y-bearing chromosomes in a fresh semen sample.

DNA content of the $\mathrm{X}$ and $\mathrm{Y}$ chromosomes as $\mathrm{X}$-chromosome has $3.8 \%$ more DNA than Y-chromosome [9]. This difference can, nonetheless, be detected with FACS technique. Before the spermatozoa are passed through the cell sorter, the sample is exposed to a nontoxic DNA dye that specifically binds to DNA to allow measurement of the DNA content of each spermatozoa. The cell suspension is then passed through an extremely fine nozzle that vibrates at high frequency causing the fluid stream to disperse into micro-drops which, optimally holds only one spermatozoa after the conditions are calibrated. When the stream of micro-droplets is passing through a UV laser beam, the already stained DNA will start to glow or emit fluorescence. The strength (intensity) of the florescence is measured by a detector, and if the florescence is in the range designated for the Y-bearing spermatozoa, that micro-drop is given an electric charge. Furthermore, if the intensity is within the range for X-bearing spermatozoa, the micro-drop is given an opposite electric charge. The charged micro-drops fall between two charged plates, resulting in two groups of droplets to be separated into different pools (Figure 1). Droplets that fall outside of the fluorescence range for $X$ or $Y$ are collected into a third group where the sex cannot be determined. The disadvantages of the technique are its relatively slow process and increased wastage of unsorted spermatozoa. The advantage is it can give up to $95 \%$ purity sexed semen samples.

\section{Application of sexed semen in goat and sheep production}

Although the sexed semen technology is gaining in popularity in commercial cattle industries, its use has yet to be developed in the sheep and goat industries. Nevertheless recent attempts to separate the $\mathrm{X}$ - and $\mathrm{Y}$-chromosomal fractions using flow cytometry on ram semen has been attempted and yielded a fraction purity greater than $90 \%$ [18]. In flow cytometry, the sperm extending medium plays a critical role in the efficiency of separation and the viability of the sperm after sorting $[19,17,20]$. Ram sperm have to be diluted 20 -fold before sorting and a further 200 -fold dilution takes place when it passes through the cell sorter resulting in capacitation-like changes that lead to reduced fertility of sexed sheep semen $[17,20]$. It has also been shown that suspension of ram semen in Tris-based medium without egg- yolk, improves the staining of the DNA and efficiency of separation of sperm without reducing its viability $[18,21,8]$.
When working with frozen sex- sorted semen in sheep, it is believed that the semen should be deposited in the oviduct or deep within the uterus to obtain high success rates, although it appears to be not as critical in cattle [16]. In sheep, frozen semen is usually deposited laparoscopically into the uterus and these same methods have been used effectively to produce offspring from frozen sexsorted semen [15]. Oviductal deposition of frozen semen in sheep is not practical if large numbers of sheep are to be inseminated. To our knowledge, there have been no reports of attempts to inseminate sheep or goat using sex- sorted semen in the cervix or transcervically.

The minimum number of sperm in an intrauterine $\mathrm{Al}$ dose in sheep varies between $5 \times 10^{6}$ and $25 \times 10^{6}$, but in Australia it has been suggested as $25 \times 10^{6}$ motile spermatozoa. Although it is not known exactly the minimum number of frozen sex-sorted sperm for intrauterine insemination of sheep, it is expected that it should be in the range of standard commercial intrauterine AI semen dose [20]. However, it is acceptable that the number of sperm in frozen sexsorted semen should be increased in line with the negative effects of the sorting process to obtain high efficiency.

The timing of Al also plays a significant role in Al success in sheep but recent findings have suggested that the best results can be achieved with sex-sorted frozen sperm when inseminated just before the expected ovulation time in ovulation-synchronized progesterone treated ewes. Using sex sorted frozen semen (40 million sperm per AI dose), optimal results can be expected when ewes are inseminated at $58 \mathrm{~h}$ after sponge removal or $36 \mathrm{~h}$ after GnRH injection [20].

\section{Embryo production and transfer}

Multiple ovulation and embryo transfer (MOET): This breeding model has been extensively used to multiply genetically superior goats and sheep and many protocols have been developed to optimize its application in research as well as in commercial practice [22-25]. In most domestic farm animals, especially in cattle, the genetic gain is limited on the female side due to low reproductive rate with only one calf being produced per year and also relatively long intervals between generations. To overcome these limitations MOET has been developed. Using this method, a female is hormonally stimulated to have multiple ovulations (superovulation). Most MOET programs in sheep and goat consist of a 14 to 17 day progesterone exposure, with FSH injections beginning 2 days before the removal of the progesterone releasing device. Following six or eight FSH injections given twice daily, the animals are allowed to breed naturally or by artificial insemination. The ovulated ova are allowed to fertilize in vivo following artificial insemination or natural mating. After fertilization and initiation of embryo development, 6-7 day old embryos (morula/ blastocyst stage) are recovered from within the uterus using embryo flushing techniques. In sheep, this is done surgically [26]. These embryos are then transferred to non-pregnant estrus-synchronized recipients 6-7 days post estrus or frozen in liquid nitrogen $\left(-196^{\circ} \mathrm{C}\right)$ for future use.

It is well-known that the superovulation protocols in small ruminants do not guarantee the recovery of quality transferable embryos due to various factors that affect the success of the program [25]. These factors can be listed as extrinsic and intrinsic factors. The extrinsic factors include: a) source and purity of the gonadotrophins, b) protocol of gonadotrophin injection, and c) the type of progesterone treatment protocol [25]. Intrinsic factors include: age, breed, nutrition and reproductive status of the animals [25]. However, despite all the achievements in the MOET programs in small ruminants so far, the success of obtaining high quality transferable embryos still remains 


\begin{tabular}{|l|l|l|l|l|}
\hline Species & Transferable embryos & Transferred embryos \\
\hline & & Fresh & Frozen & Total \\
\hline Sheep & 18828 & 4793 & 433 & 5226 \\
\hline Goat & 3141 & 824 & 278 & 1102 \\
\hline Cervids & 980 & 840 & 0 & 840 \\
\hline
\end{tabular}

Source: Embryo transfer Newsletter, IETS, September 2009

Table 1: World embryo transfer activity in small ruminants in 2008 .

low and more studies are needed to investigate the optimization of these programs.

\section{Embryo transfer (ET)}

According to the available data from the International Embryo Transfer Society (IETS), the number of embryo transfers carried out in small ruminants is shown in Table 1. In sheep and goat, ET is usually carried out by laparoscopic surgery 6-7 days post estrus [27], (Figure 2). Estrus is generally synchronized in sheep as follows. On day-1 of the program, progesterone releasing intravaginal sponges $\left(\right.$ Veramix ${ }^{\circledR}, 60 \mathrm{mg}$ medroxyprogesterone acetate, Pharmacia \& Upjohn, Orangeville, Canada) are inserted in to the vagina. On day14, the sponges are removed and 300 IU PMSG (Folligon ${ }^{\circledR}$, Intervet) are injected intramuscularly to each ewe at the time of sponge withdrawal. Vasectomised rams are introduced on day- 15 and ewes in estrus are identified between $12-36 \mathrm{~h}$ post PMSG injections. Surgical embryo transfer is then performed on day-22 of the program [27].

The embryos are usually evaluated for morphology according to the IETS criteria [28] and only the excellent quality blastocysts/ morulae are transferred into recipient ewes. Ewes are anesthetized using xylazine $(0.2 \mathrm{mg} / \mathrm{kg})$ injection intravenously, and are secured on a laparoscopic cradle. An incision of approximately $1 \mathrm{~cm}$ is made in the skin approximately $3 \mathrm{~cm}$ to the left of the mid line and approximately $5 \mathrm{~cm}$ from the udder, using a scalpel blade (Figure 2B-D). A trochar and cannula are inserted into the abdominal cavity through the incision made in the skin (Figure 2E-F). The uterine horns and the ovaries with corpora lutea are visualized using a laparoscope (Figure 2G). The uterine horn is punctured close to the utero-tubular junction using a blunt 18-gauge needle and the embryos are loaded into an embryo transfer catheter and transferred into the lumen of the uterine horn (Figure $2 \mathrm{H}$ ). The ewes are then monitored postoperatively for a few hours and released to the paddocks.

Recently, a goat ET group in Sri Lanka reported that they have produced ET born goat kids (Figure 2B) from fresh embryos in a field embryo transfer program without using sophisticated equipment [22], thus validating the field application of the technique in veterinary practice to multiply genetically valuable goats to establish an elite goat herd under local production conditions. Moreover, ET in small ruminants is still carried out using the conventional ET techniques employing laparoscopic techniques with an average pregnancy rate of $60 \%$ with fresh embryo transfers. The pregnancy rates can vary due to many factors such as donor, recipient, embryo and operator. The transcervical ET procedure seems to be not practical in these species due to the problems associated with handling of the cervix and its anatomy. Recently, a research group [29] reported that anestrus sheep cervix can be dilated using prostaglandin $12 \mathrm{~h}$ prior to the insertion of AI gun into the uterus suggesting possibility of transcervical ET in sheep. However, more studies are needed to optimize this technique in small ruminants to obtain high success rates.

\section{In vitro embryo production in sheep and goat}

In vitro embryo production in sheep and goat provides an alternate source of low cost embryos for transfer in breeding programs such
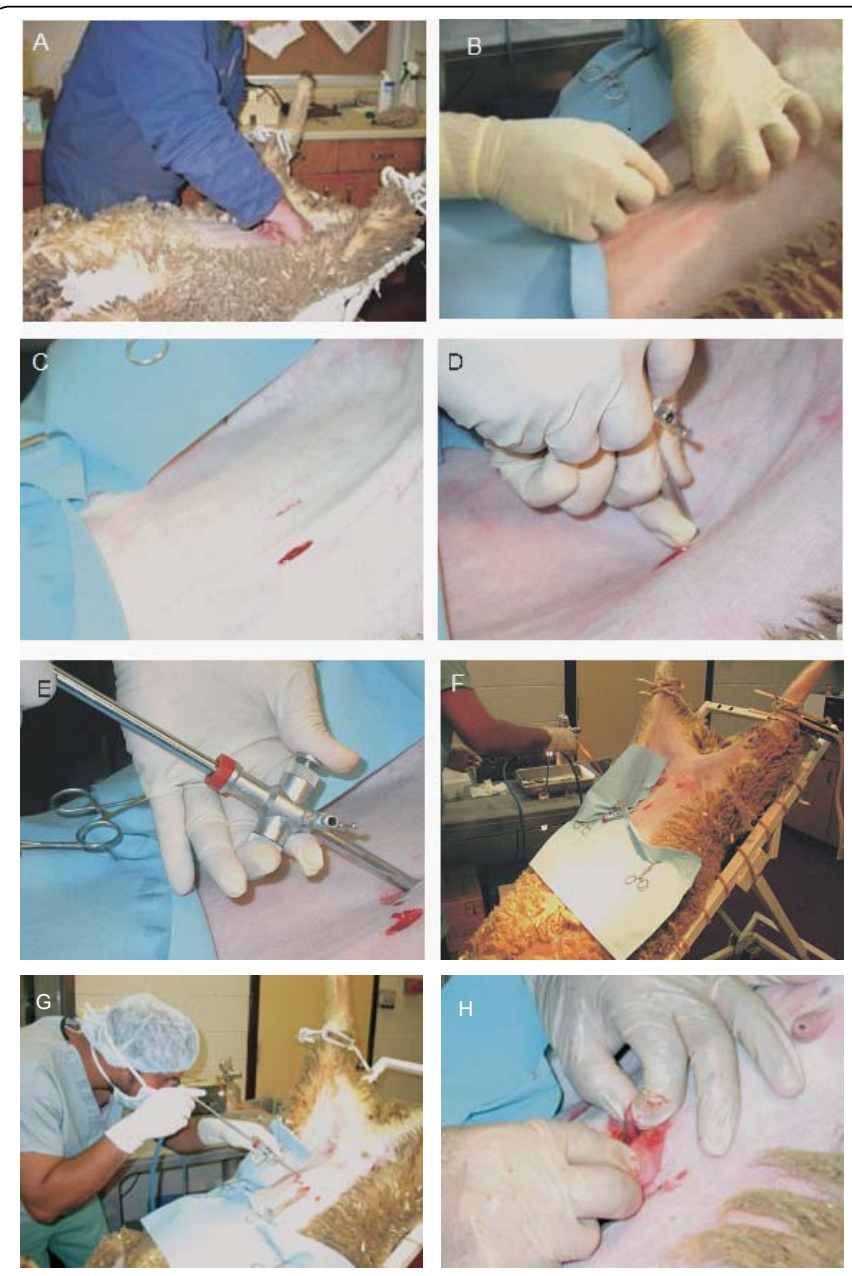

Figure 2: Embryo Transfer in sheep and goat. Embryo Transfer in sheep and goats $(\mathbf{A}-\mathbf{H})$ : $(\mathbf{A})$, preparation of anesthetized ewe on a cradle; $(\mathbf{B})$ and $(\mathbf{C})$, two skin incisions (each $1 \mathrm{~cm}$ ) are made on either side of the mid ventral line, 5 $\mathrm{cm}$ away from the udder; (D, E and F), insertion of trocar and cannula, cannula is left on the abdomen through which endoscope is inserted into the abdomen; (G), insertion of the endoscope through the cannula to visualize the ovaries, corpora lutea and reproductive tract; $(\mathbf{H})$, a uterine horn is punctured close to the utero-tubular junction using a blunt-end 18 Gauge needle, embryos are loaded into an ET catheter and transferred into the lumen.

as MOET. The process consists of 3 main steps: 1) oocyte collection and In vitro maturation (IVM) of cumulus-oocyte complexes (COCs), 2) In vitro fertilization (IVF) and 3) in vitro culture of embryos. These steps have been reviewed in detail by others [30 - 33]. Here we will highlight the important differences between species.

\section{Oocyte collection and In vitro maturation}

Prior to in vitro fertilization, COCs are collected either by minimally invasive laparoscopic ovum pick up (LOPC) or postmortem from slaughtered females [32,34]. Cumulus-oocyte complexes are collected from live sheep by a laparotomy followed by aspiration of oocytes from ovaries using an aspiration pump. This method is often called as laparoscopic ovum pick-up (LOPU) and seems to be very efficient for the recovery and quality of the COCs obtained in sheep and goats. Usually, in sheep, a short repeated gonadotrophin treatment is followed by LOPU [35-38]. In contrast, goats can be stimulated with a 'one shot' regime of gonadotrophins (one shot of follicular stimulating hormone (FSH) plus equine chorionic gonadotrophin (eCG), compared to the traditional multi-dose 
gonadotrophin regimes. The results revealed no differences in the efficiency of COCs recovered and their quality $[39,36]$. It has also been shown that 'one shot' regime can be performed as a 4-day treatment regime followed by LOPU in sheep and goats without reducing the efficiency in oocyte recovery and quality [40]. The most common method of oocyte collection is from abattoir derived ovaries from sheep or goat. Ovaries are transported to the laboratory at $37^{\circ} \mathrm{C}$ in phosphate buffered saline (PBS) after which they are finely sliced with a scalpel blade and rinsed in oocyte collection medium consisting of $2 \%$ steer serum in Ham's F10 medium [34].

In vitro maturation of abattoir derived oocytes from sheep and goats (for comprehensive reviews see 32,31 ) rely on methods based on bi-carbonate buffered TCM 199 medium supplemented with L-glutamine, ovine FSH $(10 \mu \mathrm{g} / \mathrm{ml})$, ovine $\mathrm{LH}(10 \mu \mathrm{g} / \mathrm{ml}$, estrogen $(1 \mu \mathrm{g} / \mathrm{ml})$ and $10 \%$ fetal bovine serum [34]. Some researchers have used mature follicular fluid supplementation in the IVM medium to enhance the maturation of sheep oocytes [31]. Under these conditions, goat and sheep oocytes tend to extrude first polar body between 16-24 h of in vitro maturation [41]. In contrast, it is accepted that supplementation of the glutathione precursor cysteamine $(100$ $\mu \mathrm{M})$ in IVM medium enhances the in vitro maturation process of goat oocytes [41]. In addition, a recent study [42] showed that cysteamine and BSA added to IVM medium for sheep, resulted in high blastocyst rates ( $42 \%$ blastocyst rate from total cultured oocytes) and high survival rate of blastocysts after embryo transfer. It is obvious that artificial oocyte maturation and culture systems have detrimental effects on embryo development compared to their in vivo counterparts. Recent fluorescent in situ hybridization cytogenetic studies from our laboratory using whole chromosome painting probes have revealed that high incidence of chromosomal abnormalities in sheep blastocysts derived from IVP systems, compared to in vivo derived blastoctsts [43] emphasizing the inherent differences in the two production methods.

\section{In vitro fertilization}

In vitro fertilization of the oocytes is usually carried out following $24 \mathrm{~h}$ maturation in the IVM medium. Surrounding cumulus cells are removed by gentle pippetting and washing in fertilization medium and groups of 40-50 oocytes are placed in 4-well dishes in $500 \mu \mathrm{l}$ of synthetic oviductal fluid (SOF) covered by $200 \mu$ of mineral oil $[31,43]$. Motile sperm are obtained by centrifugation of frozen-thawed semen in Percoll gradient $(45 \% / 90 \%)$ at $500 \mathrm{~g}$ for $10 \mathrm{~min}$ in room temperature. Percoll gradient separation of spermatozoa seems to be an effective means of yielding motile sperm from frozen-thawed semen [44]. Motile sperm are collected from the bottom of the $90 \%$ fraction and diluted to a concentration of $10^{7}$ spermatozoa $/ \mathrm{ml}$ in media. Recent studies have shown that incubation of spermatozoa for a further 1 $\mathrm{h}$ period in media supplemented with heat-inactivated estrus serum enhances the capacitation process of spermatozoa (sheep and goat : [41]; deer : $[45,46]$ ). In our laboratory we routinely add heat inactivated sheep serum ( $2 \%$ ) to the IVF medium and incubate oocytes with motile spermatozoa for 17 hours resulting acceptable levels of blastocyst development [43]. Although $17 \mathrm{~h}$ co-incubation is practiced in IVF, it has been shown that even $4 \mathrm{~h}$ co-incubation was enough to obtain acceptable cleavage and blastocyst rates in sheep [41]. Further application of in vitro fertilization in obtaining sex pre-determined offspring will be an advantage for the livestock industry $[47,20]$. In vitro fertilization of prepubertal oocytes and oocytes recovered from LOPU [37] are also important areas to be developed further.

\section{In vitro culture}

Following in vitro fertilization, embryos are washed several times

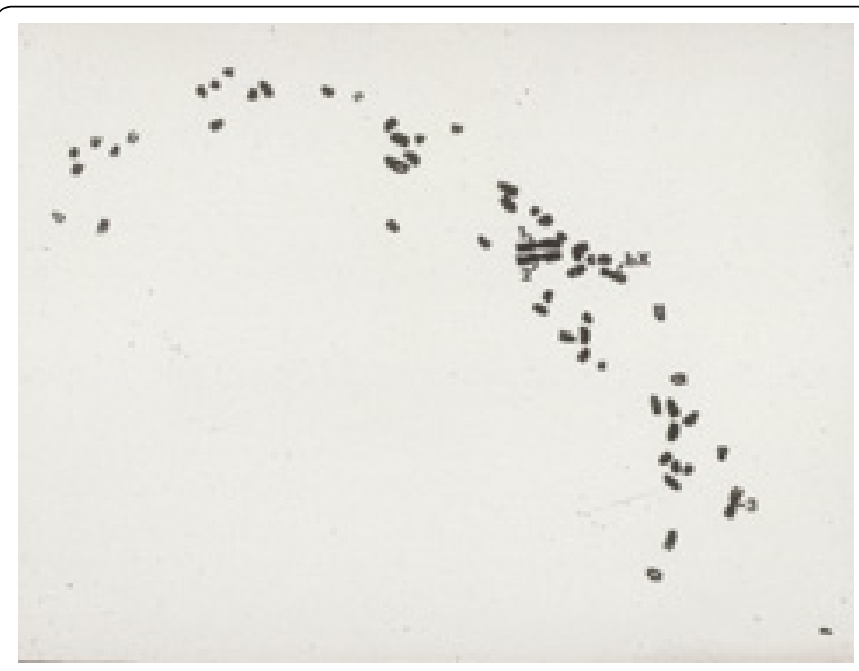

Figure 3: Metaphase spread from a 4-cell sheep-cattle hybrid embryo showing 57 chromosomes ( 30 cattle and 27 sheep). Note the 3 metacentric sheep chromosomes labeled 1,2 and 3 and the cattle $X$ chromosome labeled bX. (King and Kelk, unpublished data).

and then placed in in vitro culture (IVC) media for further development. There are 3 methods available for embryo culture after fertilization, such as co-culture with somatic cells, culture in semi-defined media and culture of embryos in in vivo systems (oviducts) of the same or different species [41]. Co-culture systems in sheep and goat are usually based on including oviductal cells in TCM-199 medium. Semi-defined medium is also used often in small ruminant IVC based on the components of the sheep oviductal fluid (SOF), a medium containing essential and non-essential amino acids supplemented with BSA $[48,43]$. In our laboratory, sheep embryos cultured in SOF medium supplemented with amino acids and BSA at $38^{\circ} \mathrm{C}$ in $5 \% \mathrm{O} 2$, $5 \% \mathrm{CO} 2,90 \% \mathrm{~N} 2$ humidified atmosphere resulted in $19.2 \%$ blastocyst rates from total oocytes cultured [43]. This rate is confirmed by [38], who showed that SOF culture systems supplemented with BSA and amino acids produce high quality blastocysts in sheep. Addition of fetal bovine serum (FBS) on day 2 or 3 of culture does result in high embryo survival post-embryo transfer and normal viable offspring [41]. However, some studies have reported that sheep embryos reduce their viability by $15 \%-25 \%$ when produced in SOF systems supplemented with serum compared to co-culture [48] or in in vivo systems of culturing the embryos in oviducts [49]. It has been noted that adding steer serum or human serum to sheep and goat IVC media may attribute to many abnormalities in the offspring [50,51].

\section{Interspecies in vitro fertilization}

Investigating interspecies fertilization provides valuable insights into the role of cytoplasmic and nuclear events that regulate full term development. Due to species specific molecular, morphological and chronological markers these embryo models are unique for examining the paternal and maternal interactions and their vital role in development. Interesting findings from our laboratory revealed that ram spermatozoa is not able to fertilize bovine oocytes in vivo, however, in vitro fertilization occurs and the resulting hybrid embryos, confirmed by cytogenetic analysis (Figure 3), arrested at 4-8 cell stage [52] even when zygotes were transferred to sheep oviducts for early development. Similar developmental arrest occurs with the reverse cross. Hybridization between sheep and goats through cross or chance breeding like many species, appears to be polar with the success or efficiency dependent of the parent of origin 
[53]. Goats bred to rams conceive and pregnancies will progress to second trimester while in the case of the reverse cross, sheep oocytes exposed to buck sperm in vivo do not fertilize [52]. However, a few cases of sheep X goat hybrids born to goats have been documented [54]. In vitro sheep and goat oocytes, could be fertilized by buck or ram sperm and embryos developed to the blastocyst stage, hatched and, following transfer into the uteri of sheep or goats, they established pregnancies. However, retarded fetal growth, defects in placentome formation and pregnancy failure during the second month of gestation were observed [52]. The in vitro production of hybrid embryos is particularly amenable to facilitate further study of the reproductive barriers and species differences in imprinted and epigenetic, regulation of early embryo development that are key to embryo survival and development.

\section{Somatic cell nuclear transfer (Cloning)}

A new era in reproductive biotechnology began when Wilmut and colleagues produced the first somatic cell nuclear transfer (SCNT) derived viable sheep, "Dolly", from transplanting an adult somatic cell into an enucleated sheep oocyte [55]. Following this breakthrough, theoretically, it seems to be a promising technology to produce unlimited numbers of genetic copies from an adult animal or a fetus; and so far many species including farm, pet and endangered animals have been cloned using this technology [56]. Obtaining a viable offspring through this technology still imposes a great challenge for researchers due to its relatively low success rate and in some instances compromised health status of offspring $[57,58)$. At present, cloning is carried out for biomedical and research purposes, and agriculture production. Although extensive reviews are available on animal cloning, here we emphasize some recent findings that are important in small ruminant cloning.

The standard SCNT technique in sheep/goat in most of the laboratories follows some common steps such as oocyte maturation, removal of cumulus cells from oocytes, enucleation, transplantation of the somatic cell into the perivitelline space of the oocyte, electrofusion of the cell couplet, activation of the embryo and in vitro embryo culture. When the embryos develop to blastocyst, they are transplanted into the uteri of estrus-synchronized surrogate animals 6-7 day post estrus [27]. In most cases, the oocytes are collected from abattoir ovaries using the slicing method and undergo IVM for $17 \mathrm{~h}$ (goat: [59-61], Sheep: [34,27]). Some laboratories that conduct goat SCNT programs preferred in vivo derived oocytes either following ovulation $[62,63]$ or LOPU $[64,65]$. This may be due to the decreased availability of goat abattoirs in different countries or the higher success rates from in vivo matured oocytes. Following maturation, the cumulus cells are removed by vortexing in 3\% Sodium citrate medium [27] for $1-2$ minute or in $0.01 \%$ hyaluronidase. Cumulus -free oocytes with first polar body extrusion are selected and after a short exposure to cytochalasin B and Hoechst stain, enucleation is carried out in a micromanipulator equipped with UV light $[27,64,65,61]$. Following oocyte enucleation, cell cycle-synchronized donor cells are transplanted into the perivitelline space of the oocytes in a manner that both cell membranes attach firmly to each other. The cellcouplets are then electrofused in a $0.3 \mathrm{M}$ mannitol fusion medium. One hour following fusion, cell-couplets are activated by culturing for $5 \mathrm{~min}$ in ionomycin containing medium followed by culturing them in 6-DMAP or cycloheximide containing medium [34,27,61]. Recent studies in our laboratory revealed that a greater incidence of chromosomal abnormalities occur when SCNT-sheep embryos are cultured in 6-DMAP containing medium compared to cycloheximide $[34,27]$. After activation, embryos are cultured in IVC medium and are surgically transferred into uteri of estrus -synchronized ewes [27] or into the oviducts of the does [61]. Pregnancy confirmation is done by ultrasound scanning beginning on day 35 of pregnancy. Pregnancy loss in sheep following SCNT-derived embryo transfer can be monitored by ultrasound imaging combined with serum progesterone levels [27].

Recently, there has been some controversy on the biological age of the SCNT-derived offspring, and whether they may susceptible for pre-mature death compared to their age-matched control counterparts [56]. A good example of this was the premature death of "Dolly". The hypothesis behind this is that donor somatic cells from adults may correlate with offspring carrying shortened telomere lengths compared to normal controls. Telomeres are located at the end of the chromosomes and become shorter in each cell cycle when somatic cells replicate. When the telomere length reaches a critical length the cell either enters senescence or enters a 'crisis' state associated with the development of cancer cells. This phenomenon does not happen in the germ line and in embryonic cells as these cells posses telomerase, an enzyme that adds telomere sequences to chromosomes during cell replication thus preventing telomere shortening from occurring. In most somatic cells, the telomerase enzyme is not present, leading to continuous telomere shortening when cells replicate [66].

Recent findings in telomere lengths in animal clones revealed cases of shorter [67, 68], , not different [69-71] and surprisingly even longer lengths compared to those measured in their agematched control counterparts [72]. These findings have triggered much speculation on the fate of clones. However, this makes animal clones derived from adult somatic cells appropriate models for studying cellular rejuvenation and aging in vivo since they are generated from aged and culture propagated somatic cells known to contain shorten telomeres. Following SCNT, the differentiated donor nucleus undergoes extensive remodeling and reprogramming by the recipient oocyte cytoplasm [73], which has been shown to cause altered gene expression profiles [74] and chromatin modifications [75] that likely contribute to the high incidence of abnormalities, prenatal and post natal losses found in clones[73]. Altered expression of telomerase activity [71] and donor cell type-dependent telomere length differences [76] further support inappropriate genome reprogramming, however, the precise etiology of altered telomere lengths in vivo are not clear for clones. Recent studies from our laboratory on SCNT-derived small ruminants showed that shortened telomere lengths in sheep cloned using adult donor cells compared to controls [67] and a similar phenomenon was observed in SCNTderived goats [77]. Interestingly, the offspring derived from natural breeding between cloned parents, did not show any discrepancies in telomere length [67] suggesting that telomere length was reset in the germ line of the cloned offspring. To date we do not possess enough data on telomere length of clones and "Dolly" cannot be considered the only incidence in this nature, thus more research is needed to investigate the lifespan of cloned offspring; at this stage the data available is inconclusive.

\section{Production of transgenic sheep and goats}

Transgenic animals are produced either to carry an exogenous gene or to have a "knock out" gene from their own genome. Many transgenic animals have been produced for biomedical research interests as well as to test their application in livestock production [78]. There are many techniques available for the production of transgenic animals, such as pronuclear microinjection $[79,80,37]$, 
Citation: Alexander B, Mastromonaco G, King WA (2010) Recent Advances in Reproductive Biotechnologies in Sheep and Goat. J Veterinar Sci Technol 1:101. doi:10.4172/2157-7579.1000101

sperm-mediated transgenesis [81] and somatic cell nuclear transfer[82,65,83]. During the last decade, research has focused on producing transgenic animals which secrete recombinant proteins in their milk. These animals produce relatively high quantities of recombinant proteins compared to other conventional methods due to the physiological nature of the mammary gland for its unique ability to synthesize proteins $[84,78,85,86,87,88]$. A few examples of transgenic small ruminants producing recombinant proteins in milk for pharmaceutical and biomedical interest are sheep producing human clotting factor VIII [89] and factor IX [82] and goats synthesizing human antithrombin III [90], human alpha-fetoprotein [91], human monoclonal antibodies [92, 93], malaria antigens [94] spider silks [95], human granulocyte colony stimulating factor (96) and human butyryl-cholinesterase $[97,98]$. Although these animals have shown high expression of the transgene product in the milk, a recent report suggests that the transgene may have some negative effects on the physiology of mammary gland function, leading to a compromised situation [87]. However, the first protein produced by transgenic animals, ATryn, a recombinant human anti-thrombin$\alpha$ produced in transgenic goats' milk, received approval for use in humans in 2009.

\section{Conclusions}

In this review, we have focused on some aspects of reproductive biotechnology that are of veterinary and biomedical importance in sheep and goat that have been reported in the recent past. It is wellknown that most biotechnologies take many years to come into full practice after enormous amounts of laboratory and field research. Therefore, more focus should be carried out in emerging areas like artificial insemination of sheep and goat using sexed semen, in vitro and in vivo embryo production systems, transgenic animal production and cloning using stem cells.

\section{Acknowledgements}

The authors gratefully acknowledge the assistance provided by Ed R Reyes, Elizabeth St. John, Pamela Hasson in the University of Guelph, the MITACS Accelerate internship program, Canada, the Canadian Commonwealth Scholarship Plan and the University of Peradeniya in preparation of this manuscript.

\section{References}

1. Zygoyiannis D (2006) Sheep production in the world and in Greece. Small Rumin Res 62: 143-147.

2. Ghadar F, Spindler H (2005) The growth of biotechnology. Industrial Management 47: 19-26.

3. Polge C (1968) Frozen semen and the A.I. Programme in Proc. $2^{\text {nd }}$ Tech. Conf. Artif. Insem. Reprod. NAAB, Columbia, MO: 46-51.

4. Johnson LA, Rath D, Vazquez JM, Maxwell WMC, Dobrinsky JR (2005) Preselection of sex of offspring in swine for production: current status of the process and its application. Theriogenology 63: 615-624.

5. Johnson LA, Flook JP, Hawk HW (1989) Sex preselection in rabbits: live births from $X$ and $Y$ sperm separated by DNA and cell sorting. Biol Reprod 41: 199-203.

6. Garner DL (2001) Sex-sorting mammalian sperm: concept to application in mammals. J Androl 22: 519-526.

7. Seidel GE Jr, Garner DL (2002) Current status of sexing mammalian spermatozoa. Reproduction 124: 733-743.

8. Evans G, Hollinshead FK, Maxwell WMC (2004) Preservation and artificial insemination of sexed semen in sheep. Reprod Fertil Dev 16: 455-464.

9. Seidel GE, Schenk JL, Herickhoff LA, Doyle SP, Brink Z, et al. (1999) Insemination of heifers with sexed sperm. Theriogenology 52: 1407-1420.

10. Vazquez JM, Martinez EA, Parrilla I, Roca J, Gill MA, et al. (2003) Birth of piglets after deep intrauterine insemination with flow cytometrically sorted boar spermatozoa. Theriogenology 59: 1605-1614.
11. Rath D, Ruiz S, Sieg B (2003) Birth of female piglets following intrauterine insemination of a sow using flow cytometrically sexed boar semen. Vet Rec 152: 400-401.

12. Buchanan BR, Seidel GE, McCue PM, Schenk JL, Heickhoff LA, et al. (2000) Insemination of mares with low numbers of either unsexed or sexed spermatozoa. Theriogenology 53: 1333-1344.

13. Lindsey AC, Schenk JL, Graham JK, Bruemmer JE, Squires EL (2002) Hysteroscopic insemination of low numbers of flow sorted fresh and frozen thawed stallion spermatozoa. Equine Vet J 34: 121-127.

14. Catt SL, Catt JW, Gomez MC, Maxwell WMC, Evans G (1996) The birth of male lamb derived from an in vitro matured oocyte fertilized by intra-cytoplasmic injection of a single presumptive male sperm. Vet Rec 139: 494-495.

15. Hollinshead FK, O'Brien JK, Maxwell WMC, Evans G (2002) Production of lambs of pre-determined sex after the insemination of ewes with low numbers of $\mathrm{X}$ - or Y-chromosome bearing spermatozoa. Reprod Fertil Dev 14: 503-508.

16. Garner DL, Seidel GE Jr (2003) Past, present and future perspectives on sexing sperm. Can J Anim Sci 83: 375-384.

17. Maxwell WMC, Johnson LA (1997) Chlortetracycline analysis of boar spermatozoa after incubation, flow cytometric sorting, cooling or cryopreservation. Mol Reprod Dev 46: 408-418.

18. Hollinshead FK, O' Brien JK, Gillan L, Mayers M, Maxwell WMC, et al. (2004) Liquid storage of flow cytometrically sorted ram spermatozoa. Theriogenology 62 : 587-605.

19. Catt SL, O'Brian JK, Maxwell WMC, Evans G (1997) Assessment of ram and boar spermatozoa during cell-sorting by flow cytometry. Reprod Domestic Anim 32: 251- 258.

20. Hollinshead FK, Gillan L, O'Brian JK, Evans G, Maxwell WMC (2003) In vitro and in vivo assessment of functional capacity of flow cytometrically sorted ram spermatozoa after freezing and thawing. Reprod Fertil Dev 15: 351-359.

21. De Graaf SP, Gillan L, Evans G, Maxwell WMC, O'Brian JK (2004). The effect of the sheath fluid on the quality of sex-sorted ram spermatozoa. Reprod Fertil Dev 16: $284-285$

22. Perera GDRK, Pushpakumara PGA, De Silva LNA, Alexander B (2008) Production of genetically superior goats through embryo transfer technology in Sri Lanka. Tropi Agri Res 20: 177-184.

23. Bartlewski PM, Alexander BD, Rawlings NC, Barrett DMW, King WA (2008) Ovarian responses, hormonal profiles and embryo yields in anoestrus ewes superovulated with Folltropin- $\mathrm{V}$ after pretreatment with medroxyprogesterone acetate (MAP)- releasing vaginal sponges and a single dose of estradiol-17 $\beta$ (E217ß). Reprod Domest Anim 43: 299-307.

24. Bartlewski PM, Alexander BD, King WA (2008a) Ovarian and endocrine determinants of superovulatory responses in anestrous ewes. Small Rumin Res 75: $210-216$.

25. Gonzalez-Bulnes A, Baird DT, Campbell BK, Cocero MJ, Garcia-Garcia RM, et al (2004) Multiple factors affecting the efficiency of multiple ovulation and embryo transfer in sheep and goats. Reprod Fertil Dev 16: 421-435.

26. Menchaca A, Vilarino M, Pinczak A, Kmaid S, Saldana JM (2009) Progesterone treatment, FSH plus eCG, GnRH administration, and Day 0 Protocol for MOET programs in sheep. Theriogenology 72: 477-483.

27. Alexander B, Coppola G, Mastromonaco GF, John ES, Reyes ER, et al. (2008) Early Pregnancy Diagnosis by Serum Progesterone and Ultrasound in Sheep Carrying Somatic Cell Nuclear Transfer - Derived Pregnancies. Repro Domest Anim 43: 207-211.

28. String fellow and Seidel (1998) Manual of the International Embryo Transfer Society.

29. Candappa IBR, Bainbridge HC, Price NT, Hourigan KR, Bartlewski PM (2009) A preliminary study on the suitability of Cervidil to induce cervical dilation for artificial insemination in ewes. Res Vet Sci 87: 204-206.

30. Garcia-Garcia R, Ward F, Fair S, O'Meara C, Wade M, et al. (2007) Development and quality of sheep embryos cultured in commercial G1.3/G2. 3 sequential media. Anim Reprod Sci 98: 233-240.

31. Cognie Y, Poulin N, Locatelli Y, Mermillod P (2004) State-of-the-art production, conservation and transfer of in-vitro-produced embryos in small ruminants. Reprod Fertil Dev 16: 437-445.

32. Wani NA (2002) In vitro maturation and in vitro fertilization of sheep oocytes. Small Rumin Res 44: 89-95. 
Citation: Alexander B, Mastromonaco G, King WA (2010) Recent Advances in Reproductive Biotechnologies in Sheep and Goat. J Veterinar Sci Technol 1:101. doi:10.4172/2157-7579.1000101

Page 7 of 8

33. Wang S, Liu Y, Holyoak GR, Evans RC, Bunch TD (1998) A protocol for in vitro maturation and fertilization of sheep oocytes. Small Rum Res 29: 83-88.

34. Alexander B, Coppola G, Di Berardino D, Rho GJ, St John E, et al. (2006) The effect of 6-dimethylaminopurine (6-DMAP) and cycloheximide (CHX) on the development and chromosomal complement of sheep parthenogenetic and nuclear transfer embryos. Mol Reprod Dev 73: 20-30.

35. Alberio R, Olivera J, Roche A, Alabart J, Folch J (2002) Performance of a modified ovum pick-up system using three different FSH stimulation protocols in ewes. Small Rumin Res 46: 81-87.

36. Baldassarre H, Wang B, Kafidi N, Keefer C, Lazaris A, et al. (2002) Advances in the production and propagation of transgenic goats using laparoscopic ovum pickup and in vitro embryo production technologies. Theriogenology 57: 275-284

37. Baldassarre H, Wang B, Kafidi N, Gauthier M, Neveu N, et al. (2003) Production of transgenic goats by pronuclear microinjection of in vitro produced zygotes derived from oocytes recovered by laparoscopy. Theriogenology 56: 83-839.

38. Wan PC, Haoa ZD, Zhoub P, Wua Y, Yanga L (2009) Effects of SOF and CR1 media on developmental competence and cell apoptosis of ovine in vitro fertilization embryos. Anim Reprod Sci 114: 279-288.

39. Baldassarre H, Furnus CC, De Matos DG, Pessi H (1996) In vitro production of sheep embryos using laparoscopic folliculocentesis: Alternative gonadotrophin treatments for stimulation of oocyte donors. Theriogenology 45: 707-717.

40. Gibbons A, Bonnet FP, Cueto MI, Catala M, Salamone DF, et al. (2007) Procedure for maximizing oocyte harvest for in vitro embryo production in small ruminants. Reprod Dom Anim 42: 423-440.

41. Cognie Y, Baril G, Poulin N, Mermillod P (2003) Current status of embryo technologies in sheep and goat. Theriogenology 59: 171-188.

42. Accardo C, Dattena M, Pilichi S, Mara L, Chessa B, et al. (2004) Effects of recombinant human $\mathrm{FSH}$ and $\mathrm{LH}$ on in vitro maturation of sheep oocytes: embryo development and viability. Anim Reprod Sci 81: 77-86.

43. Coppola G, Alexander B, Di Berardino D, St John E, Basrur PK, et al. (2007) Use of cross-species in-situ hybridization (ZOO-FISH) to assess chromosome abnormalities in day- 6 in vivo- or in vitro-produced sheep embryos. Chromosome Res 15: 399-408.

44. Rho GJ, Hahnel AC, Betteridge KJ (2001) Comparison of oocyte maturation times and of three methods of sperm preparation for their effects on the production of goat embryos in vitro. Theriogenology 56: 503-516.

45. Comizzoli P, Mermillod P, Cognie Y, Chal N, Legendre X, et al. (2001) Successful in vitro production of embryos in red deer (Cervus elaphus) and the sika deer (Cervus nippon). Theriogenology 55: 649-659.

46. Berg DK, Thompson JG, Asher GW (2002) Development of In Vitro Embryo Production Systems for Red Deer (Cervus Elaphus). Part 3. In Vitro Fertilisation Using Sheep Serum as a Capacitating Agent and the Subsequent Birth of Calves. Anim Reprod Sci 70: 85-98.

47. O' Brien JK, Hollinshead FK, Maxwell WMC (2004) In vivo development capacity of in vitro produced embryos derived from sex-sorted and re-cryopreserved frozen-thawed ram-sperm. Reprod Fertil Dev 16: 286.

48. Hoshi $\mathrm{H}$ (2003) In vitro production of bovine embryos and their application for embryo transfer. Theriogenology 59: 675-685.

49. Holm P, Walker SK, Seamark RF (1996) Embryo viability, duration of gestation and birth weight in sheep after transfer of in vitro matured and in vitro fertilized zygotes cultured in vitro or in vivo. J Reprod Fertil 107: 175-181.

50. Sinclair KD, McEvoy TG, Maxfield EK, Maltin CA, Young LE, et al. (1999) Aberrant fetal growth and development after in vitro culture of sheep zygotes. J Reprod Fertil 116: 177-186.

51. Walker S, Hill J, Kleeman D, Nancarrow C (1996) Development of ovine embryos in synthetic oviductal fluid containing amino acids at oviductal fluid concentrations. Biol Reprod 55: 703-708.

52. Kelk DA (1997) Development characteristics of interspecific hybrid embryos. PhD Thesis. University of Guelph, Ontario, Canada.

53. Anderson GB (1988) Interspecific pregnancy: barriers and prospects. Biol Reprod 38: $1-15$

54. Pinheiro LEL, Guimaraes SEF, Almeida IL, Mikich AB (1989) The natural occurrence of sheep X goat hybrids. Theriogenology 32: $987-994$.

55. Wilmut I, Schnieke AE, McWhir J, Kind AJ, Campbell KH (1997) Viable offspring derived from fetal and adult mammalian cells. Nature $385: 810-813$

56. Vajta G, Gjerris M (2006) Science and technology of farm animal cloning: state of the art. Anim Reprod Sci 92: 211-230.

57. Hill JR, Roussel AJ, Cibelli JB, Edwards JF, Hooper NL, et al. (1999) Clinical and pathological features of cloned transgenic calves and fetuses (13 case studies) Theriogenology 51: 1451-1465.

58. Rho GJ, Coppola G, Sosnowski J, Kasimanickam R, Johnson WH, et al. (2007) Use of somatic cell nuclear transfer to study meiosis in female cattle carrying a sex-dependent fertility-impairing X-chromosome abnormality. Cloning Stem Cells 9: 118-29.

59. Ma S, Lan G, Miao Y, Wang Z, Chang Z, et al. (2003) Hypoxanthine (HX) inhibition of in vitro meiotic resumption in goat oocytes. Mol Reprod Dev 66: 306-313.

60. Lan GC, Han D, Wu YG, Han ZB, Ma SF, et al. (2005) Effects of duration concentration and timing of ionomycin and 6-dimethylaminopurine (6-DMAP) treatment on activation of goat oocytes. Mol Reprod Dev 71: 380-388.

61. Lan GC, Chang ZL, Luo MJ, Jiang YL, Han D, et al. (2006) Production of Cloned Goats by Nuclear Transfer of Cumulus Cells and Long-Term Cultured Fetal Fibroblast Cells Into Abattoir-Derived Oocytes. Mol Reprod Dev 73: 834-840.

62. Zou X, Wang Y, Cheng Y, Yang Y, Ju H, et al. (2002) Generation of cloned goats (Capra hircus) from transfected foetal fibroblast cells, the effect of donor cell cycle. Mol Reprod Dev 61: 164-172.

63. Behboodi E, Memili E, Melican DT, Destrempes MM, Overton SA, et al. (2004) Viable transgenic goats derived from skin cells. Transgenic Res 13: 215-224.

64. Keefer CL, Stone RK, Bhatia B, Lazaris A, Begin I, et al.(2000) Efficient production of viable goat offspring following nuclear transfer using adult somatic cells. Biol Reprod 62: 192.

65. Keefer CL, Baldassarre H, Keyston R, Wang B, Bhatia B, et al. (2001) Generation of dwarf goat (Capra hircus) clones following nuclear transfer with transfected and nontransfected fetal fibroblasts and in vitro-matured oocytes. Biol Reprod 64 849-856.

66. Xu J, Yang X (2003) Will cloned animals suffer premature aging - the story at the end of clone's chromosomes. Reprod Biol Endocrinol 1: 105-110.

67. Alexander B, Coppola G, Perrault SD, Peura TT, Betts DH, et al. (2007) Telomere length of sheep clones and their offspring. Mol Reprod Dev 74: 1525-1537.

68. Shiels PG, Jardine AG (2003) Dolly, no longer the exception: Telomeres and implications for transplantation. Cloning stem cells 5: 157-160.

69. Jiang L, Carter DB, Xu J, Yang X, Prather RS, et al. (2004) Telomere lengths in cloned transgenic pigs. Biol Reprod 70: 1589-1593.

70. Betts DH, Bordingnon V, Hill JR, Winger Q, Westhusing ME, et al. (2001) Reprogramming of telomerase activity and rebuilding of telomere length in cloned cattle. Proc Natl Acad Sci USA 98: 1077-1082.

71. Tian XC, Xu J, Yang X (2000) Normal telomere lengths found in cloned cattle. Nat Genet 26: 272-273.

72. Lanza R, Cibelli JB, Blackwell C, Cristofalo VJ, Francis MK, et al. (2000) Extension of cell life- span and telomere length in animals cloned from senescent somatic cells. Science 288: $665-669$.

73. Reik W, Dean W (2002) Epigenetic reprogramming: back to the beginning. Nature 420: 127.

74. Humpherys D, Eggan K, Akatsu H, Friedman A, Hoechedlinger K, et al. (2002) Abnormal gene expression in cloned mice derived from embryonic stem cell and cumulus cell nuclei. Proc Natl Acad Sci USA 99: 12889-12894.

75. Dean W, Santos F, Stojkovic M, Zakhartchenko V, Walter J, et al. (2001) Conservation of methylation reprogramming in mammalian development: aberrant reprogramming in cloned embryos. Proc Natl Acad Sci USA 98: 1373413738.

76. Miyashita N, Shiga K, Yonai M, Keneyama K, Kobayashi S, et al. (2002) Remarkable differences in telomere lengths among cloned calves derived from different cell types. Biol Repro 66: 1649-1655.

77. Betts DH, Perrault SD, Petrik J, Lin L, Favetta LA, et al. (2005) Telomere length analysis in goat clones and their offspring. Mol Reprod Dev 72: 461-470.

78. Wheeler MB, Walters EM, Clark SG (2003) Transgenic animals in biomedicine and agriculture: outlook for the future. Anim Reprod Sci 79: 265-289.

79. Ebert KM, Selgrath JP, DiTullio P, Denman J, Smith TE, et al. (1991) Transgenic 
Citation: Alexander B, Mastromonaco G, King WA (2010) Recent Advances in Reproductive Biotechnologies in Sheep and Goat. J Veterinar Sci Technol 1:101. doi:10.4172/2157-7579.1000101

Page 8 of 8

production of a variant of human tissue-type plasminogen activator in goat milk: generation of transgenic goats and analysis of expression. Biotechnology 9: 835838

80. Baldassarre H, Wang B, Gauthier M (1999) Embryo transfer in a commercial transgenic production program using $B E L E^{\circledR}$ goat embryos. Theriogenology 51 : 415.

81. Celebi C, Guillaudeux T, Auvray P, Vallet-Erdtmann V, Jegou B (2003) The making of "transgenic spermatozoa". Biol Reprod 68: 1477-1483.

82. Schnieke AE, Kind AJ, Ritchie WA, Mycock K, Scott AR, et al. (1997) Human Factor IX transgenic sheep produced by nuclear transfer of nuclei form transfected fetal fibroblasts. Science 278: 2130-2133.

83. Keefer CL, Lazaris A, Keyston R (2002) Cloning using somatic cells for the production and propagation of transgenic Nigerian dwarf and dwarf-crossed goats. Theriogenology 57: 422

84. Houdebine LM (2000) Transgenic animal bioreactors Transgenic Res 9: 305-320.

85. Keefer CL (2004) Production of bioproducts through the use of transgenic animal models. Anim Reprod Sci 82: 5-12.

86. Baldassarre H, Wang B, Pierson J, Neveu N, Sneek L, et al. (2004) Prepubertal Propagation of Transgenic Cloned Goats by Laparoscopic Ovum Pick-Up and in Vitro Embryo Production. Cloning Stem Cells 6: 25-29.

87. Baldassarre H, Hockley DK, Dore M, Brochu E, Hakier B, et al. (2008a) Lactation performance of transgenic goats expressing recombinant human butyrylcholinesterase in the milk. Transgenic Res 17: 73-84.

88. Baldassarre H, Hockley DK, Olaniyan B, Brochu E, Zhao X, et al. (2008b) Milk composition studies in transgenic goats expressing recombinant human butyrylcholinesterase in the mammary gland. Transgenic Res 17: 863-872.

89. Niemann H, Halter R, Carnwath JW, Herrmann D, Lemme E, et al. (1999) Expression of blood clotting factor VIII in the mammary gland of transgenic sheep. Transgenic Res 8: 237-247.
90. Zhou Q, Kyazike J, Echelard Y, Meade HM, Higgins E, et al. (2005) Effect of genetic background on glycosylation heterogeneity in human antithrombin produced in the mammary gland of transgenic goats. J Biotechnol 117: 57-72.

91. Parker MH, Birck-Wilson E, Allard G, Masiello N, Day M, et al. (2004) Purification and characterization of a recombinant version of human alpha-fetoprotein expressed in the milk of transgenic goats. Protein Expr Purif 38: 177-183.

92. Young MW, Meade H, Curling JM, Ziomek CA, Harvey M (1998) Production of recombinant antibodies in the milk of transgenic animals. Res Immunol 149: 609610.

93. Pollock DP, Kutzko JP, Birck-Wilson E, Williams JL, Echerlard Y, et al. (1999) Transgenic milk as a method for the production of recombinant antibodies. J Immunol Methods 231: 147-157.

94. Behboodi E, Ayres SL, Memili E, O'Coin M, Chen LH, et al. (2005) Health and reproductive profiles of malaria antigen-producing transgenic goats derived by somatic cell nuclear transfer. Cloning Stem Cells 7: 107-118.

95. Karatzas CN, Zhou FJ, Huang Y, Duguay F, Chretien N, et al. (1999) Production of recombinant spider silk (BioSteel ${ }^{\circledR}$ ) in the milk of transgenic animals. Transgenic Res 8: 476-477.

96. Ko JH, Lee CS, Kim KH, Pang MG, Koo JS, et al. (2000) Production of biologically active human granulocyte colony stimulating factor in the milk of transgenic goat. Transgenic Res 9: 215-222.

97. Cerasoli DM, Griffiths EM, Doctor BP, Saxena A, Fedorko JM, et al. (2005) In vitro and in vivo characterization of recombinant human butyrylcholinesterase (Protexia) as a potential nerve agent bioscavenger. Chem Biol Interact 158: 363365.

98. Huang YJ, Huang Y, Baldassarre H, Wang B, Lazaris A, et al. (2007) Recombinant human butyrylcholinesterase from milk of transgenic animals to protect against organophosphate poisoning. Proc Natl Acad Sci USA 104: 13603-13608. 